\title{
Understanding the New Evolution of Life: from the Biosphere to the Post-biosphere Picture of the World
}

\author{
Eduard Demidenko \\ Faculty of Economics and Management \\ Bryansk State Technical University \\ Bryansk, Russia \\ 7 50-let Oktyabrya Boulevard \\ Bryansk, Russian Federation 241035 \\ E-mail: eadergacheva2013@yandex.ru
}

\author{
Elena Dergacheva \\ Faculty of Economics and Management \\ Bryansk State Technical University \\ Bryansk, Russia \\ 7 50-let Oktyabrya Boulevard \\ Bryansk, Russian Federation 241035 \\ E-mail: eadergacheva2013@yandex.ru
}

\begin{abstract}
The concept of the scientific picture of the world reflects its essential and substantive aspects, principles and laws of world's existence and development. The change of biosphere-biological evolution that has been self-developed for 4 billion years to post-biosphere one including the analysis of global socio-natural processes is focused on. The evolutional progress and transformation of the biosphere life began with organizing human society enabling people to become free turning off biospheric life shackles and changing collective activities to producing economy: beginning with agricultural pattern and then creating industrially capitalistic one with urban technosphere based on science and technology. The preservation of the biosphere life is a problem that can be solved on condition that the UNO and all the nations of the world using their good will make a difficult decision to join their efforts for saving it.
\end{abstract}

Keywords-biosphere; technosphere; postbiosphere life; formation of sociotech nological life

\section{INTRODUCTION}

The results of the research on integrated sociotechnogenic processes and socio-technogenic development of the world, conducted at the scientific and philosophical school of Bryansk State Technical University (2002-2018) are presented by the authors in the report. This analysis has given new ways of understanding and making conclusions concerning Earth's biosphere life transformation both in the process of self-development of the biosphere and under the influence of modern humanity. Undoubtedly, much has been analyzed by philosophers and scientists, especially geologists, soil scientists, ecologists, sociologists, historians and others. One of the difficulties is that there are about 500 sciences in the world, investigating different related objects, phenomena and processes. Therefore, it is not easy to make general outline either in the field of the integral development of the world on Earth or in the ways of its progress. Taking into consideration that world's changes are resulted from many factors, futurology considers making predictions for long periods of time impossible. The authors dare to give a longterm forecast due to the fact that they have noticed such kinds of phenomena ignored by previous researchers as rapid growth in the world of socio-techno-natural processes caused by social life that with the help of science, engineering and technology creates absolutely new life phenomenon on the planet. This is a so called technosphere or artificial world.

This new level of research and global analysis was mostly achieved due to visionary predictive conclusions made by V.I. Vernadsky and his followers of the abovementioned school. Before its appearance E.S. Demidenko investigated the processes of urbanization and technogenic development of the world and its negative effect on nature of human beings including ways of social technogenic world progress with further taking turns of life evolutions. E.A. Dergacheva has researched various technogenic processes of public development, biosphere transformations and also socio-techno-natural globalization. N.V. Popkova has studied the details of the technosphere formation in the process of urbanization, technospherization and ecologization of the earth's world. N.N. Lapchenko has contributed to finding out all the extremely negative effects of the informatization responsible for information and technogenic social development. These theoretical studies, together with the significant use of statistical and sociological data have made possible to predict the process of the Earth and humanity development reflecting the picture of the biosphere destruction in spite of its being selfdeveloping one. It allows understanding how life, in general, flows from the soil biosphere house to the urban technosphere. What is most important is that authors have managed to investigate the marked change in the evolution of life on Earth and predict the timing of the inevitable death of the biosphere, if humanity does not stop choosing this bourgeois-technocratic way of social progress.

\section{METHODS}

As shown by the research of Russian scientist V.I Vernadsky and then French researchers E. Leroy, P. Teyara de Charden in the twentieth century, on the planet there was a change in the evolution of life under the influence of the collective mind and the formation of the noosphere started its way. They did not understand the essence and contents of historical changes in the biosphere, just paying attention to the trends of unification of mankind. What will happen, in 
fact, if humanity neither unites, nor becomes associated continuing their way of development in conditions of capitalism. Vernadsky was confident in the inevitable formation of the associated human race of communistic nature in fact. Noosphere theorists noted in the right way the increasing role of mankind in the progressive development of the biosphere, based on the cultivation and domestication of animals. Indeed, if earlier the whole biota had been changing the surface of the planet, especially the land, for hundreds of million years, now it is rapidly changing humanity that has been doing it using mind and machine work. We cannot help but agree. But at the same time, they idealized the noosphere future like communists who were waiting for paradise on Earth, built on the basis of collectivism.

If the biosphere has been self-developing for 4 billion years, then with the appearance of a person with intellect and the formation of society, mankind actively influences biosphere and creates, according to Vernadsky, a new world,it is noosphere which is the highest and last state of the biosphere [1]. In other words, we can say that these researchers have given us a new approach of studying biosphere life. It is a socio-natural approach, since the selfdevelopment of the biosphere is replaced by a social change in the biosphere nature and its life. This change has become especially prominent since the Neolithic period of time, when the collective economy was replaced by the producing one, known as agriculture. If historians have created the methodology of social history, reflecting the unity of the development of society and nature with the development of humanity, the philosophers and scientists of the Bryansk school following the ideas of Vernadsky in this unity give the leading place to public progress having the ability to organize and affect on the nature with the help of mind and work in an intensifying way.

The second thing missed by the science now is an underestimation of its fundamental role as being a support of the biosphere life development existing on the land of the biosphere biological substance, due to which $92 \%$ of living organisms feed and live while the rest of the bio-substance remains in rivers, lakes, seas and oceans. This substance prevails in two conditions: biogenic soil and living on the surface of the lithosphere and in the hydrosphere. The authors refer in this approach to a quite visible phenomenon that is the destruction of the soil covering being the basis of biosphere life. Since the era of agriculture soil has been uncovered and constantly used by cultivating alongside with domestication of plants and animals. If there is no soil as the source of feeding there cannot be any living beings such as plants, animals and humans either and as a result of it a man starts using biotechnology.

Turning back to the socio-natural approach, science misses the point of the productive forces satanic role that is in their ability of giving wealth,but exhausting the life-giving elements of the biosphere. For 10 thousand years, mankind has been creating agricultural productive forces with a new social energy, called the industrial one. In 1800, the share of physical forces of people accounted for $30 \%$ of all work while the domesticated animals $-68 \%$, technical energy -
$2 \%$ [2]. But over the course of two centuries there has been a huge revolution in technological potential, which now accounts for more than $98 \%$ of all the work performed in the world. These satanic forces are resulted from technocratic capitalism, under the mask of market economy and democratic society. Their satanic nature is that they do not only exploit workers, but also consume the biosphere of nature for the sake of capital.

\section{Two SCIENTIFIC PICTURES OF THE WORLD}

Thanks to the socio-natural approach, we have almost unlimited the scope of understanding in a different way of the real evolutionary change in the current and at the same time longstanding biosphere picture of the world, which is called scientific in the mass media, non-fiction and philosophical literature, and in this case this is the only suitable meaning. But what reality we have had behind the mask of science for two hundred years till now is still unknown. This vital question of world's picture changing is not asked in the scientific literature. Open any textbook on philosophy or concepts of modern natural science you can find throughout them just information about scientific picture of the world and its concept. And what about real picture? Of course, it is difficult to describe, although it can be caught in the basic essential meaning. Even in one of the most perfect textbooks on concepts of natural science by M.I. Poteev that gives unique theories and statistics on changes in the biosphere on Earth, there is no understanding of the sociotechnogenic development of the world, including biosphere [3]. It is affected by the fact that biologists do not understand the change in the world as it is beginning with biosphere life forms and ending with post-biosphere ones that depend on neither soil cover on the planet, nor biosphere biogeochemical processes together with biosphere environment in general, but upon technosphere-urban environment with biotechnological reproduction of postbiosphere life, including human beings, however, with the pathetic remnants of the past biosphere of plants and animals.

Mankind now faces the main task: to satisfy both its vital and diverse civilized needs, and to create personal and social wealth, the excessive build-up of which contradicts the possibilities of the biosphere nature of our planet. Moreover, the bourgeois pursuit of wealth aimed at meeting basic needs of particular people, put science in a difficult position. Mostly, world science deals with orders for the removal of wealth from the bowels of the Earth, the construction of cities and enterprises, but on the whole it's the technosphere that destructs the biosphere, and people do not have any idea how to use all these resources repeatedly and preserve the biosphere with its full functions. Scientists of the world are mistaken in their views concerning the current change in the evolution of life on Earth: from biosphere-biological to socio-techno-biological, since they are absolutely in the darkness considering it to be just a global environmental problem, without taking all necessary measures to preserve the biosphere and hoping for science capable to organize life on Earth without it. In their research, the authors rely on modern achievements of philosophy and science, and their conclusions about the socio-technogenic development of the 
world and change in the evolution of life on the planet supported by the Russian Academy of Sciences (RAS) and numerous scientific organizations. This is proved by more than 30 laureate diplomas received by philosophers and scientists of the school in the period from 2007 till 2017 taking part in Russian and regional competitions, revealing a new picture of the world that is being formed and in which human life is not worth envying.

\section{CHANGE OF LIFE EVOLUTION FROM BIOSPHERE TO POST-BIOSPHERE}

All that has been going on in the world, since the first system of the producing economy can be seen in the laws of the formation of social development megatrends. The term "megatrend" is used to characterize the fundamental trends of social, natural and socio-natural development. In the book "Megatrends" by J. Neisbit the author focuses on their advantages in the well-developed society. "Yes,"- he writes: "America's new information economy is our most important megatrend, but it's just an episode in the whole picture" [4]. In fact, he has no idea of the picture of the world. The matter is that new postbiosphere perspective of a world development is mostly determined not by a centuries-old self-development of the biosphere of nature, but by "collective intelligence" of mankind, and nowadays it is science that creates the technology of the "servitude of the nature", but not the technology of biosphere preservation. This, in fact, a new megatrend of social development has been coming into existence since neolithic times: when society changes the nature of the planet in the global way, but biosphere does not turn into noosphere, as V. I. Vernadsky hoped for, and degrades instead. As a result, the socio-technological and technogenic development of the world follows the way of formation of the most complex technosphere using the resources of the biosphere [5].

Industrialization and urbanization of social and natural life, satisfying many people's needs, are accompanied by the creation of a multi - faceted artificial non-living world of technosphere[6]. It relocates inside both life and multifaceted activities of people with a noticeable acceleration of social progress and the development of biological processes in nature and human beings with simultaneous increase of biosphere life degradation in general. Due to the created better living conditions and activities in the course of industrialization and urbanization, the development of science and medicine, there is a rapid growth of the population with increasing life expectancy. At the same time it is the technosphere, that actively fills out the space of biosphere with man-made objects, reducing and suppressing biosphere nature. Under these conditions, negative trends in the development of society and the biosphere are rising. First of all, the replacement of the biosphere biological life that has existed for 3.8 billion years is rather unwanted for mankind: firstly it is connected with the appearance of the socio-biospheric evolution elements (the period of the economy of gathering), secondly it is followed by sociotechno-biosphere evolution (economy of agriculture), and at last it's the turn of socio-techno-biological evolution (from the period of industrialization and development of socio- technological world with the socio-biosphere replacement). This change in the evolution of life is already caused by the civilization of mankind, ignoring the value of the biosphere nature. This leads to the inevitable destruction of the biosphere life with very little hope for the successful development of the post-biosphere life, that is, without selfdeveloping biosphere and its soil covering.

The scale of destruction of the biosphere is proved by the data on the destruction of the biosphere biological substance on the planet. The largest resource of it was in the soil. Biosphere fertile soil for the period from the Neolithic has been decreased by 2 billion hectares with no exception of the last three centuries of industrial development which have decreased by 0.7 billion ha. more. Agriculture has now 1.5 billion hectares of soils [7], though two-thirds were destroyed.

It will be enough according to our calculations for only 150 years of life for increasing population with intensive application of mineral fertilizers and chemicals while 1 billion ha of spare soil, according to the calculations of the professor of Moscow State University A. S. Yakovlev will be used within 30-40 years [8]. That is, within 200 years, the planet's land will be absolutely bare that means no biosphere soils, but poor anthropological and technogenic man-made soils instead This prospect is quite real, as it was noted earlier, since $55 \%$ of such kind of soils are on the land of the planet now [9].

It is caused by the clearly increasing destruction of the biosphere-biotic cycle of substances with the replacement of socio-technogenic ones. The enormous losses of organic matter in the biosphere is proved by the facts of its dumping into the seas and oceans. In the opinion of Soviet scientist V. A. Kovda dealing with soil science, in the 20 s of the twentieth century, 3 billion tons of humus was washed away annually, in the $70 \mathrm{~s}-24$ billion tons [10], now it is over 30 billion tons, which requires urgent measures to stop losses. This cycle of organic matter has taken fatal features.

Modern technocratism manifests itself in the theories and practice of creation and the latest post-industrial capitalist social systems. So, $95 \%$ of biosphere forests and soils are destroyed in the USA, in European countries the situation is practically the same. Pointing to the huge losses of world soils, especially in the West, Russian soil scientist G. T. Vorobyov notes: "Amazed by groundlessness of mankind ...if it were not the basis of life" [11]. The reduction and destruction of the living substance of the biosphere of the planet has reached epic proportions. Over 300 years of industrial development, more than half of the forests have disappeared and only a third of them has remained on the planet. The peak of destruction of living organisms and their species falls on the last four decades (1970-2010), when the index of "living planet", taking into account more than 10 thousand populations of organisms, decreased by $52 \%$ [12].

All this clearly points to the fact that by the end of the century the living biosphere of the substance will remain in the range of $10-15 \%$, and the life of the planet will be mostly specified by urban technosphere with advanced 
biotechnological industries, without centuries-old natural landscapes, having been created on the planet for hundreds of million years and by the end of the twenty-first century it will end its life. If we take no measures for the development and preservation of the biosphere, then by the middle of the century a deadly collapse will have taken place that will be followed by the extinction of half of the earthlings by the end of the century.

The beginning of the transition period in the life on the planet is also clearly evident through the global transformation of man according to his civilized development. E. S. Demidenko, one of the authors of this article, made his first report in 1993 at the World's Philosophical Congress in Moscow [13]. It was about the transformations of a dual nature in the human body: the contradictory development of the social qualities and the destruction of the natural biological and mental ones, expressed by the growth of a number of "diseases of civilization" with reducing quality of people's life, especially of children caused by the deterioration of the ecological state of the planet. By information of World Health Organization, cardiovascular diseases and cancer is to blame for $90 \%$ of deaths in developed countries, while in developing countries they have less than half of such deaths [14]. The main reasons for the growth of diseases and the destruction of the gene pool of mankind are the decay of the traditional ecological niche of people, their living in technosphere-urban living conditions with environmental pollution, soil depletion and malnutrition, etc.

Now we can observe the formation of the technosphere being an unanimated artificial world of objects and electromagnetic fields which size and weight can be compared to the remnants of the biosphere living matter. The main part of this world are super-cities with multimillion population and their agglomerations, which in the process of industrialisation are combined in the global technosphere. If in 1800 there were $5.1 \%$ of citizens in the world (45 million out of 910 million earthlings), then in 2015, according to the author, they accounted 51\% (3.7 billion out of 7.3 billion earthlings). For the period of these two centuries the number of earthlings has increased about 8 times, while the number of citizens has grown 80 times. At the same time, not only humanity, but also cultivated plants and animals are also more and more being concentrated in technosphere living conditions, as the fields have already acquired industrial features. The total mass of mankind and pets in 1860 was $5 \%$ of the biomass of all terrestrial animals, in $1940-10 \%$, in 1980 - about $20 \%$, and in the early 20 -th century - $40 \%$. Besides, the third part of all vegetation is represented by already cultivated species [15].

Here we could speak about the noosphere but for the destruction of the biosphere. Don't forget that biosphere is a self-developing system and the soil cover in spite of having been greatly destroyed still remains the main foundation of the biosphere and biosphere life. Unfortunately, destructing biosphere people can't form noosphere as V.I. Vernadsky and his colleagues hoped. It is technosphere that becomes this new shell of postbiosphere life being presented in the form of two-faced Janus. It can also be called techno- noosphere, because it has already started and will continue producing the cultivated and genetically modified organisms. All this show us how rapidly life from the biosphere to the post-biosphere is being replaced under the mask of environmental problems.

\section{RECONSTRUCTION AND REVIVAL OF THE}

TRANSFORMED BIOSPHERE GENERALIZATION OF GLOBAL TRENDS IN THE EVOLUTION OF LIFE

The Megatrends mentioned above form the basis of global processes and problems, without which it is impossible to start reconstruction and revival of the transformed biosphere. The authors' task is finding out effective mechanisms for the conservation of the biosphere by reducing technogenic, artificial model of the society development and making better the world on Earth on the whole, trying to reduce significantly the consumption of biospheric and biological substances caused by repeated use. If we turn to the general statistics concerning the reduction of living biosphere biological vegetable substance, according to the prominent ecologist N. F. Reimers, it accounts for about $40 \%$ [16]. As for the amount of humus in the soil, as was shown above speaking of the destruction of the soil covering it is more than $50 \%$, even if we take into account the deposits of peatlands.

The authors suggest taking a number of measures to revive the biosphere and preserve people's health $[17 ; 18]$, but it requires joint efforts in scientific and huge organizational activities. A special role can be played by the United Nations, as well as by many international organizations, in particular, the bodies of the supranational Universal State of the Earth (USE), which are now being formed in Greece, headed by the Supreme Council of Humanity $(\mathrm{SCH})$. At the meeting of the latter in October 2016 in Athens, it was planned to adopt, following the Universal Constitution of the Earth (October 2015), the Universal Declaration on the illegality of wars on Earth, making equal crimes against nature with crimes against humanity, to balance personal savings and other bills.

If we tried to generalize all global trends, we would call the most acute, dangerously fatal for the world community and the biosphere. They are: 1) fast destruction of the biosphere, including the bulk of living matter in the forests and economic zones of the oceans and seas, as well as nutrients in the soil covering, which form the basis of the biosphere and human life; 2) the formation of the global technosphere as the foundation of social development and a new planetary shell post-biosphere life; 3) the historical change of the evolution of life: from biosphere biological to sociotechnobiological; 4) global transformation of the earthlings community in the direction of their integration with their artificial nature and as a result further formation of artificial life unity that is globally sociotechnological; 5) the transformational changes of the person from being a biosocial organism towards the sociotechnological one with further prospect of forming a cybernetic organism.

The authors suggest the most probable, in their opinion, safe and perspective moving away from mortal danger for 
man and biosphere that resulted from people's spontaneously chosen way of social and technogenic development of the world. It is based on the following ideas: 1) the arrangement of the process intended for preserving the rest of biospherebiological substance remained on the planet that has been created by self-development on land for about 400 million years. This should be achieved through global restructuring of man-made and life-threatening social (anthropogenicbiotic) circulation of substances; 2) partial restoration of biosphere spaces, especially in the regions with favourable climatic conditions and active processes of self-development; 3) making preferable conditions for human activity with further successful development of: a) full biological substance obtained by means of limited vermintechnoligical production fields, b) biotechnological productions of the technosphere that is being formed; 4) creation of large-scale processing of waste both agricultural, and industrial including other branches of production with no exception of human activity; 5) stopping any other pollution dangerous for biosphere organisms such as humans, plants, animals and microorganisms; 6) solving numerous problems connected with climatic changes on the planet; 7) rationalization of all types of life on the basis of social equality, humanism, labor contribution of everyone and his family to the production of vital goods, preservation and development of life; 8) appropriate streamline of the state and political system and the organization of peoples life. Of course, speaking about fundamental strategic ideas that give the base for creating socio-techno-biosphere model of life we mean our conscious choice taking into account the ability of biosphere self-development and its compatibility with artificial world which is rationally built on the basis of the biosphere but not on the technosphere.

\section{CONCLUSION}

The evolutionary turn in the development of life on our planet, which has reached its dangerous peak, requires the UNO's arrangement supported by the developed countries to conduct fundamental research on the socio-technological progress of the world together with the development of a full-fledged scientific program concerning practical measures for the conservation of the biosphere film of life, biosphere-biological matter and soil covering, combined with the most important directions of the planet's greening (stability of the development) adopted at UNO's conferences and also making some more decisions. The main problems are now related to the socio-technological life progress, the change of its evolution and the dispersion of the film of life. If we don't start doing it now, we will have our planet that is fortunately still alive in the condition when life of the person in esthetically designed urban community will be like in the hell.

In Russia, much depends on changes in the policy of the ruling party, doing near to nothing in the regions of soil covering conservation, being careless to biosphere biological substance, especially to forests resources, failing to take interest in more equitable distribution of income. Opposition parties are not active enough and, they do not put forward fundamental ideas of income redistribution in favour of the poor, putting up with the situation in the country when the property of the whole country's wealth is owned by a small number of its citizens. International statistics allows us to compare via the share of national income of $1 \%$ of household in any country and to reflect the imbalances in possessing income and expenditures of some people in some countries and on Earth. This figure ranges from $18 \%$ in New Zealand, Belgium and Japan, to more than $70 \%$ in such countries as Russia. For example, in India it is 53\%, in China $-39 \%$, in the USA $-37 \%$, in the UK, France and Italy $-23 \%$. As a result, $10 \%$ of the world's population has $48 \%$ of the total income of mankind and owns $75 \%$ of the planet's wellbeing, while the rest $90 \%$ of the population has got only $25 \%$ [19]. Unfortunately, in the 90-ies of XX century in Russia with the collapse of the USSR there was a mass robbery of its citizens giving the state property to "effective managers". At present Russian authorities still have done nothing to distribute wealth in a proper way. In the Constitution of RF there are tasks to built social state, but economic and political elite of the country ignores it.

A special role in preserving life is given either to the science as a whole, which is aimed at thorough studying of the development of life on Earth under the conditions of modern era of industrialization, urbanization and technosphere of the planet or to economic science, which examines the world through the prism of economic growth, welfare, neglecting the laws of biosphere-biological development of life. The well-being of people should be based not only on fair salaries or wages, but also on the full returning of waste to the production using biosphere resources in the least. "The purpose of philosophy, - says V.A. Kutyirev instead of serving science and progress, it should safeguard our life ..." [20]. But in addition to that we must explain that it means not any life, moreover not postbiosphere one that results in "concrete jungle" but biosphere life preserving all its wealth, enhancing humane material and spiritual creativity of people that does not destroy the culture of living, created by nature, and safely enters the living biosphere world of humanity and his creations.

What changes should be made under the influence of the UNO, international public organizations, the emerging Universal state of the Earth, and the states of the world in order to avoid the destruction of the biosphere and, in general, of the biosphere life on our planet and to achieve stable peace? The biosphere is a planetary unity, while humanity, separated by state borders, pursues his various interests and needs, satisfying them by using biosphere nature having no idea of the science of the biosphere. Despite all the hopes and wishes of people, mankind is unable to agree on complex contradictions existing among different states, so the need for building a Universal Sate is an important step towards the solution of preserving life on Earth.

Hence, the UNO, first of all, should solve the problem of unification of peoples against the threat of the destruction of biosphere life. Of course, the WSE's efforts cannot yield rapid results if the UNO acts passively, lobbying the interests of the powerful. But, in our opinion, it is possible to use the 
experience of uniting international forces against the threat of fascism earlier and ISIL now. The UNO Security Council in the created conditions can be united with WSE Security Council, and it can consist of 5 permanent members of the Security Council: Great Britain, China, the Russian Federation, the USA and France, all of them are nuclear states, further addition of the largest and developed countries will include, for example, India, Brazil, Germany, Iran, Egypt and Australia. It is the union of these states (or others) that is capable of disarming almost the entire world and the population, while going through disarming process to the necessary minimum by itself too, leaving the rest of armament just necessary for the preservation of public order in each country. It must sign a contract concerning the inviolability of borders. Having nuclear or other weapon these states will be able to support any legitimately elected governments and save them from encroaching on their legal power within the country or from abroad. In the context of the development of major programmes for the conservation of biosphere life, the disarmament of the world and citizens is extremely urgent, as this is the most important way of uniting for the sake of life on earth. The main thing here is the joint efforts of the UNO's states and mutual understanding between them in making decisions to eliminate this fatal danger of armament which will result in destruction of biosphere. As for international law, in that context, it will still be developed and implemented on the basis of the fundamental principles aimed at preservation of peace among peoples and strengthening of biosphere life, including other principles of justice and humanity.

\section{REFERENCES}

[1] V.I. Vernadsky, "Biosphere”. Moscow, 2001.

[2] E.A. Arab-Ogly, "The Foreseeable Future. The Social Consequences of Scientific and Technological Revolution: Year 2000". Moscow, 1986.

[3] M.I. Poteev, "Concepts of Modern Natural Sciences". Saint Petersburg: Peter, 1999.

[4] J.Naisbitt,"Megatrends". Moscow, 2003.

[5] E.S. Demidenko, E.A. Dergacheva,"Technogenic Development of Society and Transformation of the Biosphere".Moscow, 2010.

[6] N.V. Popkova, "The Philosophy of Technosphere". Moscow, 2008.

[7] M.N. Stroganova, "Land Resources of the World" in Globalistics: international interdisciplinary dictionary encyclopedia. Moscow, Saint Petersburg, 2006, pp.338-340.

[8] A.S. Yakovlev, "Problems of Soil Protection and Organic Products" in Natural Resource Statements, vol.2, Moscow, 2014.

[9] A. Katsura, Z. Otarashvilli, "Environmental Challenge: Will Humanity Survive". Moscow, 2005.

[10] V.A. Kovda, "Soil Cover Farming and Social-Ecological Problems" in Questions of sociology, L'viv, 1987, pp.149, 156.

[11] G.T. Vorobyov, "Scientific-philosophical Foundations of Soil Cover". Bryansk, 2014.

[12] M. Babenko, "Living planet" in Use and Protection of Natural Resources of Russia. Scientific- informational and problematicanalytical bulletin, vol.3 (135), Moscow, 2014.

[13] E.S. Demidenko, "Ecotechnological Apocalypsis, or "the end of the world» of a human being" in Noosphere Ascension of the Terristrial Life, Ed. E. Demidenko. Moscow, 2003.

[14] V.V. Huskin, T.A. Akimova, T.A. Trifonova, "The Ecology of a Man". Moscow, 2008.
[15] Anthropo-technogenic Degradation of the Biosphere: proposals to overcome it [Russian multidisciplinary scientific-practical conference proceedings]. Moscow: INION RAS, 2014.

[16] N.F. Reimers, "Hopes for Survivng of Mankind: conceptual ecology". Moscow, 1992

[17] E.S. Demidenko, E.A. Dergacheva, "From Global Degradation of Biosphere to the Change of Evolution of Life". Moscow: RAS, 2017.

[18] Electronic Publication: E.A. Dergacheva, O.E. Backsanskij, "Economic Man under Conditions of World Social-Technogenic Development" in The European Proceedings of Social \&Behavioural Sciences [International Conference «Responsible Research and Innovation 2016 http://www.futureacademy.org.uk/files/images/upload/icRRIF201602 5.pdfhttp://dx.doi.org/10.15405/epsbs

[19] I.I. Kondrashin, "Global Problems of Modernity and Ways of their Solving" in Bulletin of the Russian philosophical society, vol.2 (78), pp.110-115,2016.

[20] V.A. Kutirev, "Culture and Technology: Two World's Struggle". Moscow: Progress-Tradition, 2001. 